\title{
VISITA À ILHA DA PINTADA E ÀS ABORDAGENS DE PAISAGEM
}

\author{
Cristiano Quaresma de Paula*, Roberto Verdum ${ }^{* *}$
}

*Doutorando do Programa de Pós-Graduação em Geografia da Universidade Federal do Rio Grande do Sul.

E-mail: cqpgeo@gmail.com

** Professor do Instituto de Geociências e do Programa de Pós-Graduação em Geografia da Universidade Federal do Rio Grande do Sul.

E-mail: verdum@ufrgs.br

\begin{abstract}
Resumo: Neste texto é apresentada a paisagem da Ilha da Pintada (Porto Alegre, Rio Grande do Sul, Brasil) a partir de diferentes concepções teóricas e metodológicas. Com base em registros de trabalho de campo, realizados da margem da referida ilha, de barco, são apresentadas leituras da paisagem elaboradas de acordo com abordagens da geografia clássica, sistêmica, humanística, crítica e pós-moderna. Também se dá ênfase à forma, função e estrutura na compreensão da paisagem. Isso possibilitou a apresentação da paisagem descrita, sistematizada, percebida, problematizada e marcada pela cultura. Por último, são sinalizados os limites e as possibilidades de análise da paisagem decorrentes de cada método.
\end{abstract}

Palavras-chave: Teoria. Método. Paisagem. Cultura.

\section{Introdução}

Apresentamos uma discussão de cunho teórico e metodológico a respeito de algumas concepções de paisagem, na geografia, e respectivas implicações em processos analíticos. Entendemos que ao longo da constituição do pensamento geográfico o conceito de paisagem foi abordado de formas distintas e que isso implicou em leituras diversas. Assim, a partir de um trabalho de campo, realizado de barco em torno da Ilha da Pintada - Bairro Arquipélago - Porto Alegre RS, em novembro de 2011,buscaremos compreender a paisagem a partir de aportes conceituais e enfoques metodológicos distintos.

Da geografia clássica às geografias pós-modernas o conceito de paisagem foi abordado com maior ou menor importância. Desde sua concepção, na geografia clássica, o conceito de paisagem, esteve atrelado ao de cultura, como se observa nas obras Vidal de La Blache (1954) e Carl Sauer (1998). Na corrente de geografia quantitativa a ambiguidade do conceito perde espaço para o racionalismo lógico-matemático, bem como para modelos constituídos sob a perspectiva sistêmica, como propõe Bertrand (2004). Na vertente humanística segue um ponto de vista extremamente particularista que prioriza a subjetividade, como propõe Tuan (1980). Lacoste (1990) e outros, na corrente de geografia crítica, entendem que a junção de localização e ideologia determinam espaços que são escondidos na paisagem. Nessa estratégia o grupo dominante escolhe o que é bom e belo para ser revelado ou escondido. Nas geografias pós-modernas Cosgrove apud Name (2010), que também é referenciado na geografia crítica, entende paisagens de (sub)culturas em contraposição às das culturas dominantes. Já Berque (1998) apreende paisagem como uma marca, que expressa uma civilização a partir de sua materialidade.

A partir da compreensão dos enfoques de paisagem nas escolas de geografia Clássica, Quantitativa, Humanística, Crítica e Pós-Modernas buscaremos expor possibilidades de análise da paisagem da Ilha da Pintada. Para tanto, admitiremos, no campo metodológico, quatro possibilidades de encaminhamentos: descrição, sistematização, percepção e explicação. A paisagem na perspectiva da geografia clássica será apreendida a partir da sua descrição, ou seja, a análise está pautada nos aspectos visíveis. A paisagem em contexto da geografia quantitativa (positivista e neopositivista) será apreensível a partir da sua sistematização. Logo, o estudo da combinação dos elementos físicos, biológicos e sociais, uma interface entre o natural e o social. A paisagem da escola de geografia humanística será analisada a partir da percepção, logo o que é perceptível ao individuo em sua subjetividade. Na perspectiva da corrente de geografia crítica a compreensão da paisagem se dará a partir da explicação embasada teoricamente no materialismo histórico e dialético. Por fim, no contexto de geografias pós-modernas, se admite que a paisagem seja descrita, inventariada, a partir de uma percepção que carece de explicação.

\section{Paisagem Descrita}

Visitando principalmente as obras de La Blache e posteriormente de Saur, Name (2010) entende as abordagens de paisagem, na geografia clássica, de forma articulada ao conceito de cultura. Para ele a cultura é entendida tanto como o trabalho, a interação direta dos 
seres humanos com a natureza na produção, quanto como a consciência, o conjunto de ideias, valores, crenças e a ordem moral (p.165). Assim, paisagem e cultura são compostas por materialidade e imaterialidade.

E é válido dizer que:

\begin{abstract}
"Embora o termo "cultura" não seja utilizado, sua noção se apresenta, como já dito, a partir do conceito de "gênero de vida", mas também nas noções de "hábito" e de "adaptação ao meio", fatores que moldam as regiões/paisagens de cada grupamento humano. 0 "sujeito" que se relaciona com a paisagem, neste caso, é evidentemente um "sujeito coletivo"”' (NAME, 2010, 167).
\end{abstract}

Em “Princípios de Geografia Humana”, La Blache (1921) resume as suas principais ideias e propõe que cada gênero de vida possui uma localização específica na superfície da Terra e sua particular adaptação ao meio corresponde uma paisagem-tipo. Assim, compõem o conceito de paisagem as noções de forma (resumo dos diversos elementos em conexão, ao mesmo tempo causa e efeito uns dos outros) e, principalmente, de fisionomia (a expressão da singularidade de cada localização).

Quanto às formas nas paisagens Sauer aponta que estas (físicas e naturais) distinguem áreas nas paisagens. Mais do que uma cena real vista por um observador a paisagem geográfica é uma generalização derivada da observação de cenas individuais. Assim o geógrafo pode descrever a paisagem individual como um tipo ou, provavelmente, uma variante de um tipo, mas ele tem sempre em mente o genérico e procede por comparação (ibidem, p.168).

Name (2010) destaca que para Sauer existem dois tipos de paisagem: as paisagens naturais seriam aquelas "virgens", supostamente intocadas ou com pouca ação humana, enquanto que as paisagens culturais seriam as que possuem a presença do homem como agente da paisagem, avaliadas a partir das suas marcas.

Sauer (1963) apud Name (2010) define paisagem cultural como "a visão geográfica da economia de grupo, como se sustenta com comida, abrigo, mobiliário, ferramentas e transporte". O autor acredita que com esta conceituação, que em muito se aproxima da noção de gênero de vida, a paisagem tornava-se objeto central de todos os ramos da geografia. Assim, pode-se dizer que Sauer define uma forma estritamente geográfica de se pensar a cultura, a partir do estudo das marcas da ação do homem sobre as paisagens.

Diante do exposto apresentaremos uma breve paisagem descritiva, que é apresentada por Verdum (2012) como aquela que "tem como base a descrição e, para apreensão da paisagem seriam necessárias à enumeração dos elementos presentes e a discussão das formas. Assim, a análise geográfica estaria restrita aos aspectos visíveis do real e, essencialmente, a morfolo- gia da paisagem".

A descrição que segue se deu sob a observação da paisagem em trabalho de campo realizado junto ao Núcleo de Estudos Geografia e Ambiente - NEGA/UFRGS em novembro de 2011. 0 trecho corresponde às observações da Ilha da Pintada, a partir do Lago Guaíba, mais precisamente na margem situada na Rua Nossa Senhora da Boa Viagem.

"Ao acompanhar a margem da Ilha da Pintada, no sentido sul-norte, destaca-se logo no começo a presença de um estaleiro, que encontra-se em estado de deterioração e, atualmente realiza somente reparos. $\mathrm{Na}$ área do estaleiro não há vegetação na margem do Guaíba, é seguido pela rua e por residências. Estas casas seguem um mesmo padrão, pois serviam de moradia para funcionários do estaleiro. Na medida que o barco se afastava do estaleiro se observava processos de erosão na ilha, com as árvores próximas do lago. Ao fundo ainda haviam casas geminadas dos operários do antigo estaleiro. Dando seguimento foi possível ver a presença de pequenas embarcações artesanais, posicionados sob a areia submersa, nas proximidades havia vegetação, mais ao fundo tinham a rua e casas de madeira. $\mathrm{Na}$ sequência estavam presentes barcos maiores, de lata, também associado à vegetação do lago e na ilha, mais alta devido ao aterro, apareciam árvores e casas simples cercadas. Seguindo o trajeto se observou a presença de barcos, com casario, também associado a bastante vegetação do lago e, para o acesso à ilha, havia uma subida pedregosa com escada e um trapiche, na margem estava um homem de baixo de uma árvore e próximo da rua e da casa que o seguiam. Na sequência além do barco de pesca possuía um barco de passeio amarrado em um poste no lago, as embarcações estavam delimitadas e ao lado do barco de pesca a havia vegetação do lago, na margem existiam muitas árvores e na sequencia rua e casas. Mais adiante em uma área em que o aterro da ilha não era tão alto haviam pessoas molhando os pés na água do lago, ali também era possível ver arvores e pessoas sentadas em um banco de praça -uma área particular de Marina -, e no fundo rua e casas de madeira. Na continuidade foi visível duas embarcações, uma de passeio nova e outra abandonada, tinha uma corda amarrando as duas, ao fundo o mato, as árvores e a rua. Seguindo o trajeto se observou a maior presença de postes delimitando os ancoradouros de embarcações de passeio, principalmente, e na margem da ilha o aterro feito de concreto em contraste com as arvores no fundo. Mais adiante seguem os ancoradouros delimitando área dos barcos de passeio e das pequenas embarcações artesanais, havia também um trapiche 
com portão trancado, e no fundo as árvores. Seguindo se notava mais um trecho em que a areia e pedras ficavam submersas com presença de vegetação do lago, e na continuação as árvores, a rua e as residências de alvenaria. Mais a frente se observava os fundos de casas que ficavam na margem do lago, sendo possível ver utensílios da pesca e pessoas trabalhando. Algumas casas eram do tipo palafitas, de baixo delas havia areia e pedras submersas, as pequenas embarcações ficavam nas proximidades, e do outro lado da rua haviam cercas e outras casas. Mais adiante não se notava casas, mas a predominância de vegetação do lago, árvores e uma escadaria em alvenaria abandonada. Próximo do final do trajeto, na margem estavam pequenas embarcações com mulheres pescando de caniço, na parte submersa havia uma área privada com dois homens pescando e árvores. No fim do trajeto, a ilha estava bem mais alta do que a superfície da água, havia uma escada de acesso que chegava à frente da Colônia de Pescadores,

Figura 1: Relação entre embarcações artesanais e vegetação.

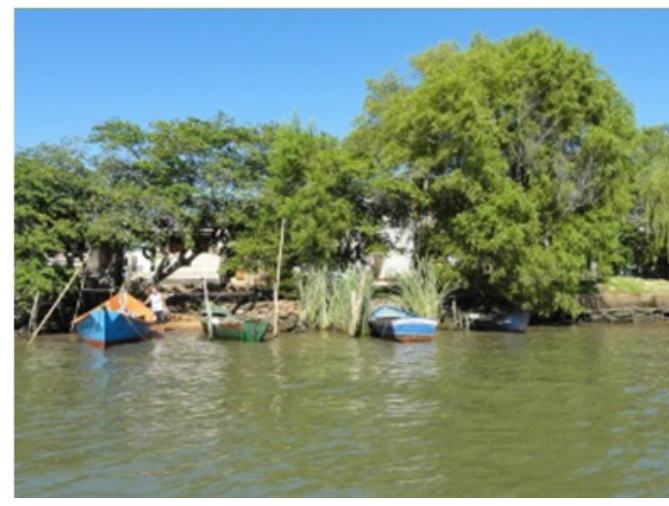

Fonte: Autor. Data: 10/11/2011

vida ou culturas tradicionais estabelecem relações distintas com o espaço. Contudo o sentido de tradicional que evocamos não se refere a algo estagnado no tempo (DE PAULA, 2013).

A ocupação da margem também revela formas e fisionomias. A descrição da observação segue a superfície da água, a margem, a rua e as casas (Figura 3). As formas das casas se distinguem ao longo do trajeto, desde casas padrão do estaleiro, a casas de madeira até casas de alvenaria com muros (Figura 4, 5). A ocupação da margem também se diferencia, inclusive quanto ao material constituinte do aterro. Existe uma relação entre áreas em que o aterro não representa uma ruptura com a margem, sendo possível verificar areia submersa no lago e casas em um padrão mais simples (Figura 3). Essa fisionomia é intercalada por áreas em que os aterros estão bem mais altos que a margem, por vezes concretados e, em vez de casas, há a instalação de marinas particulares (Figura 6). Logo na paisagem da Ilha da Pintada é possível verificar aquelas relacionadas ao modo de vida ou cultura do ilhéu pescador artesanal e um prédio antigo, branco. Ali também tinham pessoas pescando de caniço".

Nessa descrição da paisagem da Margem da Ilha da Pintada é possível extrair compreensões sobre forma e fisionomia, conforme já propõe Verdum (2012). Quanto a forma destacamos os diversos elementos que se encontravam no trajeto, bem como a relação entre eles. A relação entre embarcações de pescadores e presença de vegetação do lago (Figura 1). Ao mesmo em tempo que a vegetação do lago protege as embarcações artesanais da intemperes, os pescadores a preservam por entenderem que são necessárias para a existência da própria atividade pesqueira. Isso se expressa na fisionomia da paisagem, que permite também concluir diferentes arranjos espaciais, como a delimitação de áreas para embarcações de passeio através de postes (Figura 2), ao contrário das de pescadores que estão ancoradas próximas e junto à vegetação do lago. Nessa perspectiva frisamos a relação entre paisagem e modo de vida ou cultura de La Blache e Sauer, respectivamente. Isso nos permite compreender que modos de

Figura 2: Delimitação das embarcações de passeio.

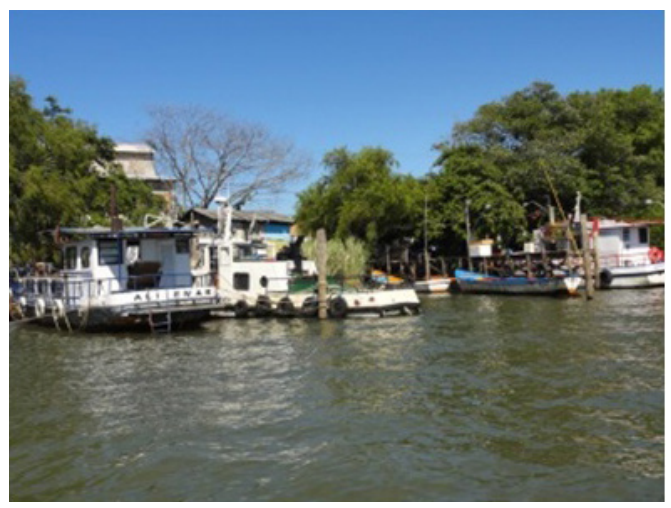

Fonte: Autor. Data: 10/11/2011

as vinculadas a outro padrão de racionalidade urbana e de funções de residência secundária e/ou lazer. Supõese que no passado a paisagem da ilha era a da pesca artesanal, contudo observamos o avanço da paisagem das embarcações de passeio, ou do turismo, sobre estas.

Figura 3: Estratificação: água, areia, rua, residência de madeira.

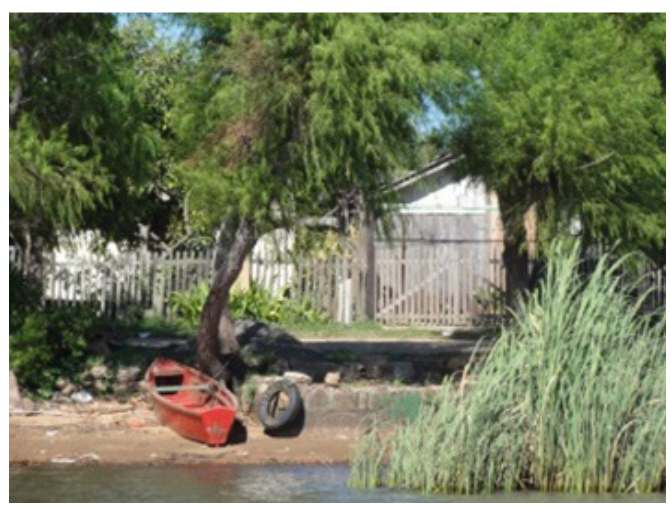

Fonte: Autor. Data: 10/11/2011 
Figura 4: Padrão de residência do estaleiro.

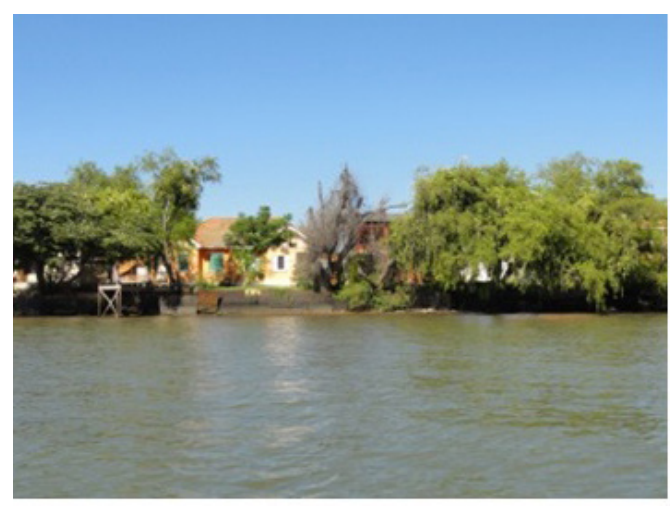

Fonte: Autor. Data: 10/11/2011

Figura 5: Residência de Alvenaria

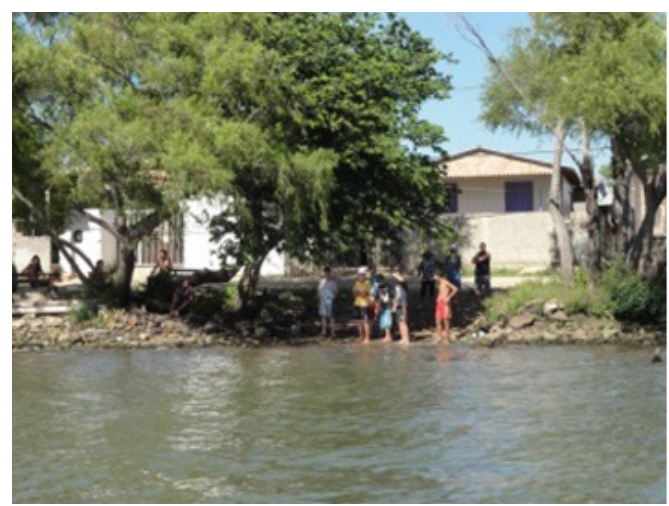

Fonte: Autor. Data: 10/11/2011

Figura 6: Aterro para Instalação de Marina

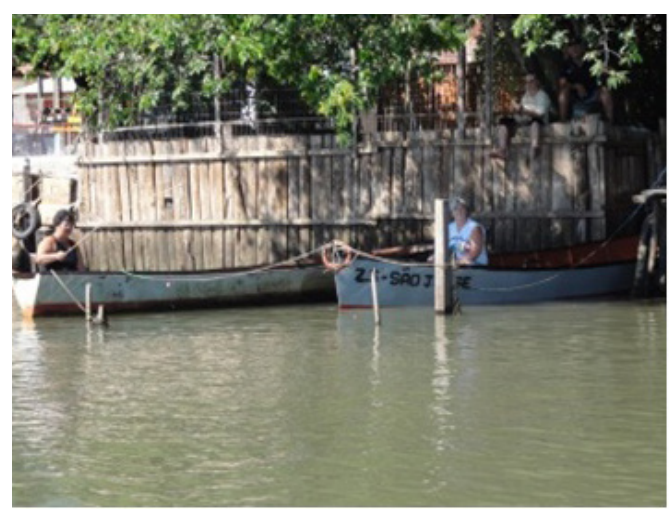

Fonte: Autor. Data: 10/11/2011

\section{Paisagem Sistematizada}

Como destaca Name (2010, p.171) na corrente quantitativa da geografia a paisagem não é um conceito ambíguo, mas compreensível através do racionalismo lógico-matemático. Complementa que esta corrente de pensamento geográfico é acusada ora de colaborar para servir aos interesses políticos e econômicos dominantes, ora de ser extremamente pragmática, racionalista, acrítica e positivista. Em contexto de neopositivismo as abordagens sistêmicas passam a compreender a ação humana, sobretudo com a definição de ação antrópica, e mais recentemente tem se introduzido a compreensão de que tais sistemas são dinâmicos e abertos.

Bertrand (2004) a partir da Teoria Geral dos Sistemas elaborou um esboço metodológico de análise da paisagem. Para o autor, a paisagem carecia de aprofun- damento epistemológico e reflexão metodológica na geografia física tradicional, na qual havia a hipertrofia dos estudos em geomorfologia e graves carências em outros, como em biogeografia.

Nessa concepção metodológica o autor destaca a necessidade de ir além da paisagem natural, mas de interligar todas as implicações da ação antrópica. Em sua classificação ele apresenta uma hierarquia entre unidades de paisagem (zona, domínio, região natural, geossistema, geofácies e geótopo). 0 autor destaca o geossistema na análise de paisagem:

Trata-se, portanto, de uma unidade dimensional compreendida entre alguns quilômetros quadrados e algumas centenas de quilômetros de quadrados. É nesta escala que se situa a maior parte dos fenômenos de interferência entre os elementos da paisagem e que evoluem as combinações dialéticas mais interessantes para o geógrafo. (...) em fim o geossistema constitui uma boa base para os estudos de organização do espaço por que ele é compatível com a escala humana (BERTRAND, 2004, p.146).

Concordante com essa perspectiva Verdum (2012) compreende que a paisagem sistêmica trata da combinação de elementos físicos, biológicos e sociais, sendo um conjunto dissociável, uma interface entre natural e social em uma análise em várias dimensões. Para o autor o "relacionamento e a análise que separam os elementos que constituem as diferentes características espaciais, psicológicas, econômicas, ecológicas, etc., não permitem, no entanto, dominar o conjunto". Assim, interessa nos estudos de paisagem sistêmica o tempo morfológico que apresenta formas, o constitucional que define estruturas e a funcionalidade, que não deve ser reduzida em partes.

Diante do exposto, a paisagem visitada em campo, quando analisada nas perspectivas de paisagem sistêmica de Verdum (2012) e de geossistêmica (BERTRAND, 2004) se apresenta como Delta do Jacuí, no qual a Ilhada da Pintada está situada. Assim caberia considerar o clima local (subtropical úmido), o relevo enquanto unidade estrutural (planície costeira do Rio Grande do Sul), bem como a biogeografia como zona equipotencial (transição entre Bioma de Mata Atlântica e Pampa).

Assim a análise se dá sobre o potencial ecológico: clima, hidrologia e geomorfologia; exploração biológica: vegetação, solo e fauna, estando estes em interação entre si e com a ação antrópica (BERTRAND, 2004, p.146). Contudo, cabe destacar que contemporaneamente as análises sistêmicas tem se atentado para compreender que estes sistemas são abertos e dinâmicos, o que tem contribuído na complexificação de tais analises (BOLÓS, CAPDEVILA, 1992, p.30)

Como este trabalho de campo não foi suficiente para uma análise geossistêmica, segundo o esboço de 
Bertrand acima citado, destacaremos alguns pontos que favoreceriam a análise. No Delta

do Jacuí desaguam as principais bacias hidrográficas do norte do Estado do Rio Grande do Sul, entre elas a do Rio Jacuí que denomina o delta. Do delta, a água conflui para o Lago Guaíba, deste para a Laguna dos Patos e desta para o Oceano Atlântico. Essa caracterização hidrológica se dá pelas características do relevo e do clima, sobretudo da precipitação. Ao mesmo tempo, influencia toda a dinâmica biótica das ilhas, sendo que por tamanha biodiversidade foi constituído o Parque Delta do Jacuí, a fim de preservar fauna e flora presentes, assim como a importância da hidrodinâmica na constituição do delta. Sobretudo, enquanto meio que oferece as condições necessárias para a conservação ou qualificação da biodiversidade, identificada no seu conjunto. Tal biodiversidade também se relaciona com a sociedade local, e aqui queremos destacar os pescadores artesanais. 0 Lago Guaíba, onde se encontra o Delta do Jacuí, se diferencia dos demais corpos de água por concentrar tanto espécies de peixes de água doce, como a piava (Leporinusobtusidens), quanto de água salobra, como a tainha (Mugilcephalus). Essa riqueza em espécies proporcionou, desde o início da ocupação das ilhas pelos açorianos e africanos o desenvolvimento da pesca artesanal, tanto para subsistência quanto comercial. Nesse contexto se configura a comunidade da Ilha da Pinta a qual é reconhecida em Porto Alegre e região como pesqueira (Figura 7).

Figura 7 - Colônia de Pescadores Z5

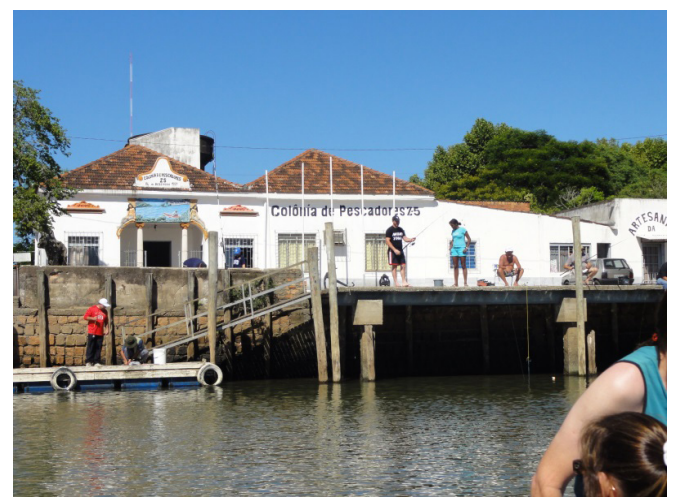

Fonte: Autor. Data: 10/11/2011

\section{Paisagem Percebida}

A percepção da paisagem se encontra no enfoque da escola da geografia humanística. Esta tem suporte da fenomenologia, sobretudo existencialista, dando ênfase às particularidades, onde a paisagem é analisada a partir dos valores, crenças, gostos, preferências e visões de mudos. Assim a análise está direcionada para as compreensões sobre a relação entre as paisagens e os pequenos grupos e seus valores. Neste contexto, a paisagem aparece como dotada de significado simbólico a partir de atitudes em relação à natureza. Com base em Lowenthal (1968), Name $(2010,172)$ destaca que ganha sentido a utilização do termo paisagens vernaculares.

Em vez de vernaculares, preferimos adotar o termo paisagens tradicionais. Compreendendo que as paisagens têm uma temporalidade presente e que está em continua transformação. Assim, quanto ao conceito de tradição:

Ousamos inferir que, frequentemente, a invenção não é tão importante quanto o processo de reinvenção, adaptação e transformação. 0 tradicional, que não nega as contradições, expressa a síntese, os consensos e as rupturas das sociedades que se distinguem a partir dos seus fazeres e saberes, os quais pressupõem uma relação dinâmica com o tempo e com o espaço (DE PAULA, 2013, p.25).

Para compreender paisagens tradicionais, sob a perspectiva da fenomenologia da percepção (TUAN, 1983), recorremos a relatos de campo anotados a partir do diálogo com dois pescadores, os Senhores Salomão e Valdir, ilhéus da Ilha da Pintada, os quais acompanharam o grupo no trabalho de campo e relatavam suas percepções enquanto o barco se aproximava da margem da ilha:

"A ilha tá muito mudada. Antigamente os moradores eram todos pescadores e moravam próximos do Guaíba. Agora nem todo mundo é pescador e tem pescadores que moram nas ruas lá de trás. Nós também conseguimos coisas, que antes a gente considerava importante. Essa parte do asfalto na rua (Nossa Senhora da Boa Viagem) acabou saindo por pressão da comunidade, mas poder mesmo nem podia. A nossa luta é por melhorias na ilha, e nas ilhas que estão em situação pior também e que os pescadores possam seguir pescando como sempre fizeram. Eu sou filho de pescador, meu irmão é presidente da colônia. Ainda tenho parentes que pescam. Hoje eu estou aposentado, mas a gente segue lutando pelo direito de quem quer seguir na pesca que possa pescar. Na conversa com a prefeitura a gente sempre busca alternativas de renda pra comunidade. Uma é o turismo e pra trazer o turista pra ilha a gente tá buscando com a prefeitura o Catamarã. A gente acha que com turismo vai ter mais chances de renda para o povo" (Valdir Coelho, 2011).

"A ilha ainda resiste por que nós estamos aqui, de olho. Outras já sumiram por causa das areeiras ilegais. É a nossa casa, toda nossa vida foi feita ali. Aqui eu criei meus filhos e netos e estou vendo nascerem meus bisnetos, semana que vem nasce outro. Mas os moradores da ilha são também minha família, criei dois rapazes que não tinha família pra cuidar. Ensino a rapaziada a pescar, a filetar peixe. Esses dias um me disse: - seu Salomão fui contratado de carteira assinada no mercado. Fiquei orgulhoso. Se não tivesse a ilha, não tinha essa família. De uns tempos pra cá todo mundo quer chegar. Viram 
que beleza é a ilha, a vista pro centro, pro Gigante da Beira Rio. Minha prima vendeu um terreno, ofereceram mais do que a gente imagina em dinheiro, vendeu né. Eu moro ali, na beira do Guaíba e não vendo por nada. Da janela de casa eu já olho se o tempo tá bom pra pesca e pra onde ir pescar. Quando a pesca tá proibida a gente trabalha no peixe, vende, e se vira. 0 peixe na taquara que a gente serve aqui na ilha é nossa criação. 0 peixe vem da pescaria do dia e a taquara vem dali, da ilha mesmo, mas ninguém é louco de destruir tudo" (Salomão Oliveira, 2011).

Segundo a percepção do senhor Valdir Coelho existe temporalidades expressas na paisagem. Ele destaca as transformações que ocorreram na paisagem a partir de memórias de como era no passado. Destaca que essas mudanças influenciaram nas formas de viver, nas relações entre os moradores, e na proximidade do pescador com o Lago Guaíba. Percebe algumas modificações como melhorias, principalmente aquelas que associam às conquistas da comunidade. Não desvincula o pescador da paisagem e destaca a luta para manter na ilha a atividade pesqueira como direito de um modo de viver. Contudo, mais do que como pescador, ele se posiciona como liderança comunitária e observa potenciais para proveito econômico da paisagem da ilha, como o turismo. A percepção do senhor Valdir Coelho está de acordo com a sua posição na comunidade, como membro de conselho do Orçamento Participativo da Prefeitura de Porto Alegre.

Ao falar da paisagem da ilha o senhor Salomão Oliveira se remete diretamente as relações sociais na ilha. Relaciona sua historia de vida à historia da comunidade da Ilha da Pintada. Para ele, falar da ilha é falar de si como individuo e cidadão. Destaca também ameaças à permanência da ilha tal como está, seja por impactos ambientais de empresas mineradoras, seja pela chegada de outros moradores ou empreendimentos externos à comunidade. Percebe que a ilha está em processo de mercantilização, pela da vista que proporciona. Inverte a analise de paisagem remetendo o olhar à outra margem do Guaíba - Centro de Porto Alegre (Figura 8), Estádio Beira-Rio-. Retoma o seu cotidiano, no qual interage com a paisagem. Sua casa está na paisagem, trabalha na paisagem, e olha pela janela para a paisagem pesqueira. Finaliza destacando que no processo de preparação do "Peixe na Taquara", a qual é prato típico da Ilha, o peixe é da ilha, bem como a taquara, mas que todos cuidam para que não se esgote. Assim, o senhor Salomão Oliveira fala enquanto pescador, que está e depende da ilha para a manutenção dos seus hábitos e práticas sociais, da mesma forma que se vê como protagonista na comunidade.

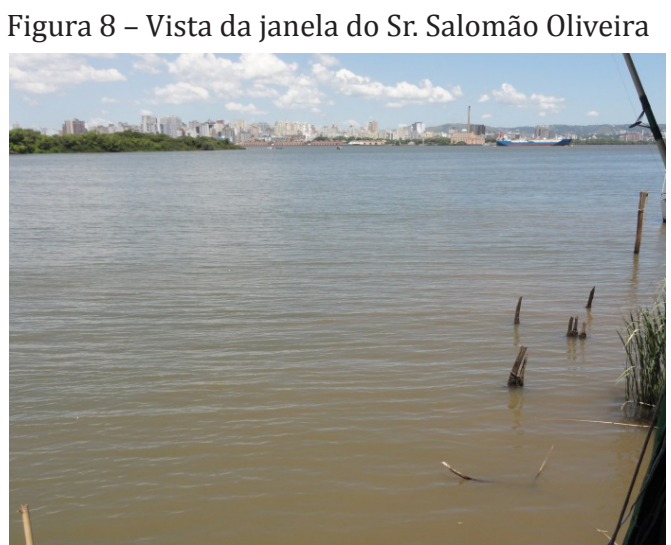

Fonte: Autor. Data: 10/11/2011

Figura 9 - Peixe sendo assado na taquara

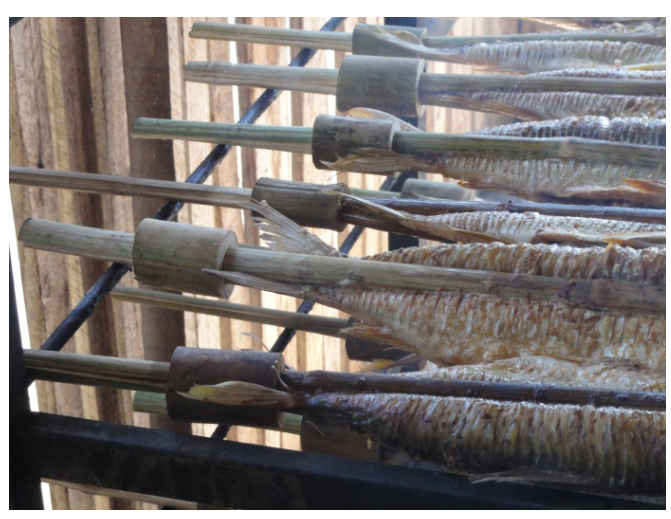

Fonte: Autor. Data: 10/11/2011

Apesar de nenhum dos dois senhores terem citado a palavra paisagem nesses trechos, cabe destacar que esta aparece como episteme inscrita nas falas. A ilha é lugar, é território e é paisagem. Contudo, não é a paisagem que se vê, mas que se está. Não é paisagem cristalizada, mas paisagem que as práticas sociais modificam e transformam. É a paisagem percebida por quem está dentro dela e que a descreve a partir da sua posição enquanto individuo no espaço.

\section{Paisagem Problematizada}

Na corrente de geografia crítica autores como Lacoste (1990) e outros elegem a paisagem como objeto de estudo, como espetáculo e parte da cultura de massa, em filmes, anúncios publicitários e cartazes turísticos. Questionam a paisagem-tipo da geografia clássica, a qual, para eles não corresponde à paisagem real, mas uma abstração que dificulta o estudo objetivo. Enquanto objeto de estudo a paisagem está sujeita a diversas criticas sendo acusada de esconder conflitos do sistema capitalista promovendo uma ilusão de hegemonia (NAME, 2010, 173). Entra em questão o ponto e vista (localização e ideológico):

0 ponto de vista de onde se observa uma paisagem (localização) torna-se importante nas análises e se confunde com o homônimo ponto de vista de quem expressa sua opinião (ideologia). É a partir da junção de ambos que determinados espaços, segundo 
tais autores, seriam escondidos ou revelados em uma paisagem. Pois, segundo Lacoste, é um grupo dominante que escolhe o que é bom e o que é belo, e há uma estratégia implícita no que se quer revelar ou esconder (NAME, 2010, p.174)

O conceito de ideologia também está presente na abordagem de Cosgrove (1998) quando propõe uma geografia cultural radical com base no materialismo histórico, em paisagens simbólicas e no conceito de formação socioeconômica. Nesse contexto o conceito de ideologia não se confunde com o conceito de cultura, que confere a paisagem uma visão bem imaterial, ela seria, para Cosgrove (idem), "uma ideia, uma maneira européia/ocidental de ver o mundo e onde o sujeito (coletivo, cada grupo ou sociedade) interpreta a si e os outros" (NAME, 2010, 176-177).

Diante do exposto, em nível explicativo, problematizaremos a paisagem enquanto produto a qual é atribuído valor de uso e de troca. A partir do trabalho de campo a problematização seguirá três eixos: mercado imobiliário, turismo e apropriação pelo Estado.

Quanto ao mercado imobiliário a paisagem se apresenta como atributo associado ao valor da terra. Embora não seja tão evidente na Ilha da Pintada, como é na Ilha das Flores - também situada no Bairro Arquipélago-, a instalação de grandes mansões, os moradores destacam o significativo aumento no valor dos terrenos. Assim a especulação imobiliária tem levado muitos moradores a venderem suas propriedades e se deslocarem para outras áreas, dentro da própria ilha, ou em outros espaços periféricos da cidade de Porto Alegre. Cabe destacar que se entende a paisagem como atributo na medida em que os terrenos situados na orla do Lago Guaíba são mais valiosos do que os estabelecidos em ruas no interior da ilha. A paisagem é mercadoria na medida em que esses novos proprietários não se vem na paisagem, eles compram "a vista”, ou seja, a outra margem do lago. Da mesma forma, por não pertencerem à mesma classe social dos demais moradores da ilha, se organizam como Organizações Não Governamentais(ONGs) para que seus interesses sejam alcançados, em espaços como os Conselhos do Parque e da APA Estadual Delta do Jacuí.

As inúmeras embarcações de passeio observadas no trabalho de campo também apontam para a proeminência do uso da paisagem para fins econômicos. Essa atividade é promovida, sobretudo pelos próprios moradores e algumas embarcações são produzidas na ilha. Devido ao gasto com a compra e manutenção das embarcações a maioria dos trabalhadores não são proprietários, e nem são formalmente contratados. Os passeios de barco são contratados principalmente por turistas, que desejam conhecer as particularidades ambientais do Delta do Jacuí. Assim, a paisagem é associada a um serviço turístico e gera todo um quadro de relações de trabalho. Analisando as embarcações na margem da ilha, já se observa que muitas estão asso- ciadas a instalação de áreas turísticas como praças e marinas, as quais excluem áreas de ancoradouros de barcos de pesca artesanal. Assim, se estabelecem duas formas de trabalho sobre o mesmo lago que, se já não incorrem, tendem a gerar conflitos por territórios.

Por fim, cabe destacar o papel do Estado na valoração da paisagem. Primeiro destacamos a criação do Parque Estadual Delta do Jacuí. Como se sabe a criação dos parques, enquanto unidades de conservação objetivam, também, a promoção de turismo (SNUC, 2000). Como destaca Becker (2002) as unidades de conservação servem de estratégia de retenção, pelo Estado, de capital de reserva para o futuro. Assim, a preservação da natureza, que se expressa na paisagem também é estratégia de Estado. Outro papel deste último, sobretudo a partir do governo municipal é de promoção da atividade turística. Muitas discussões se dão via Secretaria de Governança Local com o objetivo de envolver a comunidade nestes projetos. Além das embarcações turísticas que saem da Usina do Gasômetro, na área central de Porto Alegre, para visitação ao Delta do Jacuí, no período do Trabalho de Campo, estava em discussão a possibilidade de um catamarã fazer em diversos horários do dia o trajeto Centro Histórico de Porto Alegre - Ilha da Pintada. Nesse sentido duas paisagens são motivação, a da própria ilha e a do centro de Porto Alegre, visto da ilha.

\section{Paisagem Marcada}

As abordagens contemporâneas, ou como chamamos nesse ensaio - pós-modernas-, que daremos ênfase se inscrevem na Nova Geografia Cultural. Para esta, a paisagem resulta de um processo que é constante e inacabado e existe por si mesma, sendo uma forma de manipular e contemplar o espaço. Como destaca Name (2010), para Cosgrove a paisagem é mais do que um conceito, mas também uma ferramenta analítica do pesquisador, uma método para entender o mundo e as sociedades, as quais matem e compartilham diversas paisagens. Nesse contexto realidade e representação são mundos que se complementam e interagem entre si e que são sintetizados na paisagem. Assim ideologia, representação e cultural se fundem (p.177).

Name (2010) apresenta Cosgrove entre os geógrafos que adotaram a o materialismo histórico enquanto método de análise da paisagem. Contudo, com o tempo ele foi se afastando do materialismo histórico stricto ao ponto que em "A Geografia Esta em Todo a Parte" (COSGROVE, 1998) suas considerações sobre ideologia e poder não se referem somente às classes sociais, mas também com questões de gênero, raça, faixa etária e religião. Assim o autor esboça o conceito de paisagem de cultura dominante, como aquela que é produzida para o poder e hegemonia de um grupo sobre outro. Para Name (2010) aos poucos Cosgrove vai se interessando por temas mais abrangentes como a icnografia da pai- 
sagem, a imaginação em relação à paisagem até mesmo paisagens extraterrestres (p.177).

Na perspectiva da "Nova Geografia Cultural" a cultura não está dentro, nem funciona através de seres humanos, mas é constantemente reproduzida por eles. É como um texto que depende do contexto em que foi escrito, lido e apreendido. 0 mundo, assim, é um conjunto de textos justapostos e cabe à ciência lê-los e interpretá-los, o que jamais será imparcial (NAME, 2010, p. 178).

Berque(1998) também apresenta uma abordagem particularista e uma discussão intertextual quanto à paisagem. Para Berque:

É preciso compreender a paisagem de dois modos: por um lado ela é vista por um olhar, apreendida por uma consciência, valorizada por uma experiência, julgada (e eventualmente reproduzida) por uma estética e uma moral, gerada por uma política, etc. E, por outro lado, ela é matriz, ou seja, determina em contrapartida, esse olhar, essa consciência, essa experiência, essa estética e essa moral (BERQUE, 1998, p.86).

Berque (1998) quando analisa a paisagem diz que ela existe em primeiro lugar na sua relação com o sujeito coletivo: "a sociedade que a produz, que a reproduz e a transforma em função de certa lógica". 0 autor trabalha a paisagem em cima de duas analise, a da paisagem marca e paisagem matriz. Revela que a paisagem é marca, já que expressa uma civilização, mas que é matriz também, pois participa dos esquemas de percepção, de concepção e de ação.

Assim, o autor enfatiza que o sujeito que participa desta paisagem é coletivo, dotado de uma história e de um meio. Também, que não é somente o indivíduo, mas tudo que a sociedade condiciona este indivíduo e o supera. Desta forma, ela situa os indivíduos no seio de uma cultura, que com isso dará um sentido a sua relação com o mundo e que este sentido, nunca é exatamente o mesmo para cada individuo.

Quanto ao método de análise de paisagens marca e matriz, compreendemos como Verdum (2012) que a expressão será de uma paisagem perceptiva:

A paisagem perceptiva é concebida como uma marca e uma matriz. Como marca, a paisagem pode e deve ser descritiva e inventariada. 0 ponto de partida continua sendo a descrição da paisagem, enquanto perceptível, mas a explicação ultrapassa o campo do percebido, seja pela abstração, seja pela mudança de escala no espaço ou no tempo. A paisagem é matriz, porque participa dos esquemas de percepção, de concepção e de ação, que canalizam, em certo sentido, a relação de uma sociedade com o espaço e com a natureza. Assim, pode-se dizer que a paisagem é o concreto, ou seja, a coisa real, mas, ao mesmo tempo, é a imaginação, a representação destas coisas, as imagens.

Com base na percepção do senhor Salomão Oliveira, pescador da Ilha da Pintada, apresentada a secção "Paisagem Percebida" faremos breves apontamentos sobre nosso entendimento de paisagens marca e matriz.

"A ilha ainda resiste por que nós estamos aqui, de olho. Outras já sumiram por causa das areeiras ilegais". No início da fala o senhor Salomão já estabelece um ser coletivo "nós" enquanto moradores da ilha, os quais se diferenciam dos "outros" empresários das areeiras. Enquanto os moradores protegem a ilha, as areeiras ilegais já fizeram outras sumir. Inicialmente já podemos distinguir duas matrizes (do morador local, e do empresário), bem como duas marcar na paisagem (da preservação e da erosão por mineração). 0 trecho "É a nossa casa, toda nossa vida foi feita ali. Aqui eu criei meus filhos e netos e estou vendo nascerem meus bisnetos, semana que vem nasce outro" demonstra os vínculos com o lugar a partir das experiências vividas enquanto ilhéu, as quais compõe a matriz cultural do referido senhor.

Cabe destacar a constituição de um sujeito que é coletivo no trecho "Mas os moradores da ilha são também minha família, criei dois rapazes que não tinha família pra cuidar. Ensino a rapaziada a pescar, a filetar peixe. Esses dias um me disse: - seu Salomão fui contratado de carteira assinada no mercado. Fiquei orgulhoso. Se não tivesse a ilha, não tinha essa família”. Família aparece como definição desse grupo, que poderíamos chamar de ilhéus, comunidade, etc. Dentro desta matriz cultural ser da família constitui pertencer ao grupo e ser responsável por ele. Transmitir saberes aparece como constituinte dessa matriz cultural, de forma que esses saberes que "deixam marcas na paisagem" não pertencem ao indivíduo, mas a coletividade.

Enquanto a matriz cultural está na paisagem e interage nela a partir de saberes transmitidos no grupo. 0 senhor Salomão Oliveira apresenta o contato com outra matriz, que vê paisagem: "De uns tempos pra cá todo mundo quer chegar. Viram que beleza é a ilha, a vista pro centro, pro Gigante da Beira-Rio. Minha prima vendeu um terreno, ofereceram mais do que a gente imagina em dinheiro, vendeu né". Essa outra matriz cultural, dos novos moradores deixa marcas distintas na paisagem. Não estão vinculadas ao lugar por sentimentos de pertencimentos, mas são motivadas pela paisagem natural que contemporaneamente são de interesse da cultura dominante, seja pela emergência do movimento ecológico, seja como fuga dos centros urbanos. Estes novos moradores, não se veem na paisagem, instalam suas mansões sem se preocuparem com os impactos destas no ambiente e na paisagem. Seus interesses sempre estão no outro lado, na vista. Entre as marcas da cultura dominante sobre a paisagem destacamos a 
pressão do mercado imobiliário, no qual alguns moradores vendem seus terrenos, os quais detinham poucas infraestruturas instaladas, e são alocadas grandes propriedades com ancoradores de barcos particulares e etc.

Já a matriz cultural do ilhéu pescador se expressa no trecho "Da janela de casa eu já olho se o tempo tá bom pra pesca e pra onde ir pescar. Quando a pesca tá proibida a gente trabalha no peixe, vende, e se vira" Na paisagem da ilha está a casa, a janela, o trabalho no peixe, e essas marcas se referem ao uma forma de viver. Complementa: "O peixe na taquara que a gente serve aqui na ilha é nossa criação. 0 peixe vem da pescaria do dia e a taquara bem dali, da ilha mesmo, mas ninguém é louco de destruir tudo" discordante com a cultura dominante que extrai o quanto pode da paisagem, o pescador ilhéu tira o suficiente para a sua sobrevivência. Não vê somente os recursos ambientais presentes na paisagem, mas ela como um todo. Ali produz e reproduz culturas que se expressam no modo de viver do ilhéu e que marca a paisagem, transforma, mas não degrada.

\section{Conclusões}

Com este ensaio foi possível compreender a diversidade de possibilidades de leituras da paisagem na geografia. Ver a paisagem a partir do barco também possibilitou outra compreensão e, por isso, foi dada tanta ênfase ao trabalhador da pesca, pois essa é a sua perspectiva de observação da paisagem.

Em cada escola do pensamento geográfico existem muitas possibilidades de entendimento da paisagem. Partindo da periodização de Name (2010) buscamos compreender como as paisagens foram concebidas e com propostas de análise de Verdum (2012) realizamos breves apontamentos sobre um trabalho de campo. Isto serviu para compreender a pluralidade de possibilidades teóricas e metodológicas que existem na geografia, sendo que em nenhum momento buscamos definir qual abordagem seria a melhor. Da mesma forma possibilitou ao pesquisador observar o objeto de estudo, que já foi pesquisado durante o mestrado com os conceitos de ambiente e território, com outras "lentes" analíticas. Ainda proporcionou compreender a paisagem como um conceito horizontal, a qual expressa epistemes de outros conceitos. Na paisagem é possível observar a materialização de territorializações, lugares de pertencimento, dinâmicas ambientais e etc.

Quanto a margem observada da Ilha da Pintada, destacamos os sujeitos que estão na paisagem, que a configuram, que se identificam e vivem nela e com ela. Logo, são paisagens que expressam culturas, relações, contradições e sentimentos. Esses sujeitos são indivíduos e são coletivos, portanto são paisagens do "ser": ser Salomão, ser Valdir, ser pescador e ser ilhéu.

\section{Referências}

BECKER, B.K. et al. (org) Geografia e Meio Ambiente no Brasil. 3ạ. ed. São Paulo: Hucitec. 2002. 396 p.

BERQUE, A. Paisagem-marca, paisagem-matriz: elementos da problemática para geografia cultural. In: CORREA, R. L.; ROSENDHAL, Z. (Orgs.). Paisagem, tempo e cultura.Rio de Janeiro: Eduerj, 1998. p. 84-9.

BERTRAND. G. Paisagem e geografia física global; esboço metodológico. Trad. Olga Cruz. RAÉ GA, Curitiba, UFPR, n. 8, p. 141-152, 2004. (Trabalho publicado, originalmente, na Revue Geógraphique des Pyrénées et du Sud-Quest, Toulouse, v. 39 n. 3. p. 249-272, 1968.)

BOLÓS i PADEVILA, M. C. El Geossistema, modelo teórico delpasage. In. BOLÓS, M. (Org.). Manual de cienciadelpaisaje; teorías, métodos y aplicaciones.Barcelona: Masson, (Colección de Geografía.). 1992.

COSGROVE, D. A. Geografia está em toda parte: cultura e simbolismo nas paisagens humanas. In: CORREA, R. L.; ROSENDHAL, Z. (Org.). Paisagem, tempo e cultura: Eduerj, p. 92-121. 1998.

DE PAULA, C. Q. Gestão Compartilhada dos Territórios da Pesca Artesanal: Fórum Delta do Jacuíl (RS). Dissertação (Mestrado em Geografia) Universidade Federal do Rio Grande do Sul. Porto Alegre: 2013. Disponível em: http://hdl.handle.net/10183/78031.

LA BLACHE, P. V. D. Princípios de Geografia Humana. Lisboa: Ed. Edições Cosmos, 1954. LOWENTHAL, D. The american scene. Geographical Review, v. 58. n. 1, p. 6188, 1968

LACOSTE, Y. Paysagespolitiques.Braudel, Gracq, Reclus. S.l.: Le Livre de Poche, 1990.

NAME, L. 0 conceito de paisagem na geografia e sua relação com o conceito de cultura. In. GeoTextos, vol. 6, n. 2, dez. 2010. Pp.163-186

SAUER, C. O. A morfologia da paisagem. In: CORRÊA, R. L.; ROSENDAHL, Z. (orgs.). Paisagem, tempo e cultura. Rio de Janeiro: EdUERJ, 1998, p. 12-74.

TUAN, Yi-fu. Topofilia: Um Estudo da Percepção, Atitudes e Valores de Meio Ambiente. São Paulo: Difel, 1980. $288 \mathrm{p}$.

VERDUM, R. Perceber e Conceber Paisagem. In. VERDUM, R.; VIEIRA, L. F. S.; PINTO, B. F. \& SILVA, L. P. Paisagem: leituras, significados e transformação Porto Alegre: Editora da UFRGS. 2012. 251 p. 


\section{APPROACHES TO LANDSCAPE READING IN A VISITATION TO ILHA DA PINTADA}

Abstract: This article presents the landscape of Ilha da Pintada (Pintada Island), Porto Alegre, state of Rio Grande do Sul, from different theoretical and methodological standpoints. Based on field research data collected on a boat at the banks of the island studied, landscape readings are performed in accordance with different geographical approaches: classical, systematic, humanistic, critical, and postmodern. Form, function, and structure are also emphasized in the understanding of the landscape. Therefore, the landscape could be presented in the way that it is described, systematized, perceived, problematized and marked by culture. Finally, the article presents limitations and possibilities of landscape analysis resulting from each method.

Keywords: Theory. Method. Landscape. Culture. 